EPJ Web of Conferences 41, 06006 (2013)

DOI: $10.1051 /$ epjconf/20134106006

(C) Owned by the authors, published by EDP Sciences, 2013

\title{
Excited state dynamics of liquid water near the surface
}

\author{
Franziska Buchner ${ }^{1}$, Hans-Hermann Ritze ${ }^{1}$, Marcus Beutler ${ }^{1}$, Thomas Schultz ${ }^{1}$, Ingolf-Volker \\ Hertel $^{1}$, and Andrea Lübcke ${ }^{1, a}$
}

Max-Born-Institute for non-linear optics and short time spectroscopy, Max-Born Str. 2A, 12489 Berlin, Germany

\begin{abstract}
Time resolved photoelectron spectroscopy explores the excited state dynamics of liquid water in presence of cations close to the surface. A transient hydrated electroncation complex is observed.
\end{abstract}

The properties of liquid water are of fundamental importance to all natural sciences. Nevertheless, many properties of water remain poorly understood. This is particularly true for the properties and dynamics of electronic excited states, which have very short lifetimes (sub-100 fs) [1] and high excitation energies in the vacuum ultraviolet (VUV) region. Although the band maximum in bulk liquid water is near $8.4 \mathrm{eV}$ [2], a lowering of the absorption edge can be expected at the surface [3]. By $a b$ initio calculations, we show that, already at photon energies $<8 \mathrm{eV}$, the proximity of cations enables the direct excitation of a surface specific charge transfer state, leading to the formation of transient hydrated (cation... .electron) complexes. A surface-solvated electron may thus be temporarily stabilized by subjacent cations.

Time-resolved photoelectron spectroscopy of liquids is a new and promising tool to investigate excited state dynamics in solution. It has been applied to study the charge-transfer-to-solvent (CTTS) dynamics of iodide and the solvation and recombination dynamics of solvated electrons [4-6]. We now use this technique to study the excited state dynamics of liquid water in the presence of alkali cations at the liquid-to-vacuum interface.

A detailed description of the experiment can be found elsewhere [7]. A high-pressure liquid chromatography pump pushes the sample solution (here: solutions of different salts of concentrations in the range of 30-100 $\mathrm{mM}$ in $\mathrm{H}_{2} \mathrm{O}$ or $\mathrm{D}_{2} \mathrm{O}$ ) through a fused silica nozzle with an inner diameter of $15 \mu \mathrm{m}$ into a vacuum chamber. A continuous liquid jet in vacuum is formed.

To excite liquid water, we irradiate the liquid jet with sub- $20 \mathrm{fs}$ pulses at $160 \mathrm{~nm}(7.75 \mathrm{eV}$ photon energy, several $10 \mathrm{~nJ}$ pulse energy), which are generated by non-collinear four wave mixing in an argon gas cell [8]. A delayed pulse at $400 \mathrm{~nm}(3.1 \mathrm{eV})$ or $800 \mathrm{~nm}(1.55 \mathrm{eV})$ probes the excited state by photoionization. Photoelectrons are collected by a magnetic bottle type time-of-flight spectrometer.

A time-resolved photoelectron spectrum is shown in Fig. $1 \mathrm{a}-\mathrm{b}$ ). After excitation of the sample (at delay $\Delta \tau=0$ ), the photoelectron signal rises steeply and then decays with transient lifetimes on the fs to ps timescale (depending on solute and solvent). The average binding energy at the temporal overlap is $\sim 2.18 \mathrm{eV}$ in $\mathrm{H}_{2} \mathrm{O}$ and $\sim 2.24 \mathrm{eV}$ in $\mathrm{D}_{2} \mathrm{O}$ (cf. Fig. 1e). The average binding energy changes as function of delay time: it decreases within the first $100 \mathrm{fs}$ and then increases. At long times, the vertical binding energy of this species in water is $\sim 2.5 \mathrm{eV}$ and thus significantly smaller than the binding energy of the solvated electron in bulk water $(3.3-3.7 \mathrm{eV},[4,9-11])$. We observe a slight cation dependence of the binding energy, while the anion does not influence the energetics. As shown in Fig. 2, the photoelectron signal grows with the solute concentration, but not proportionally. Further, addition of a small amount of iodide suppresses this transient. Both observations can only be understood, if the transient is localized at the liquid-vacuum interface.

\footnotetext{
a e-mail: luebcke@mbi-berlin.de
}

This is an Open Access article distributed under the terms of the Creative Commons Attribution License 2.0, which permits unrestricted use, distribution, and reproduction in any medium, provided the original work is properly cited. 

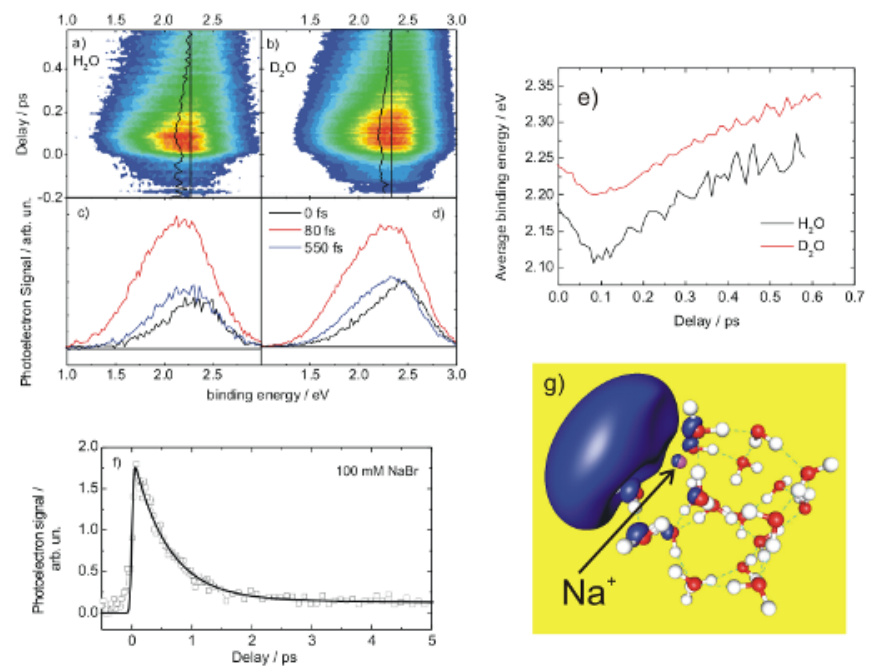

Fig. 1. Time-resolved photoelectron spectrum of a $30 \mathrm{mM} \mathrm{NaCl}$ solution in a) $\mathrm{H}_{2} \mathrm{O}$ and b) $\mathrm{D}_{2} \mathrm{O}$ ( $7.75 \mathrm{eV}$ pump, $3.10 \mathrm{eV}$ probe). Spectra for given delays are shown in c) for $\mathrm{H}_{2} \mathrm{O}$ and d) for $\mathrm{D}_{2} \mathrm{O}$. Panel e) shows the time evolution of the average binding energy for the two sample solutions. Panel f) displays the population dynamics of a $100 \mathrm{mM}$ aqueous $\mathrm{NaBr}$ solution. Panel e) shows the quilibrium geometry of the cationic cluster (used for the $a b$ initio calculations) including the spin density (blue color) of the neutral cluster after electron attachment.
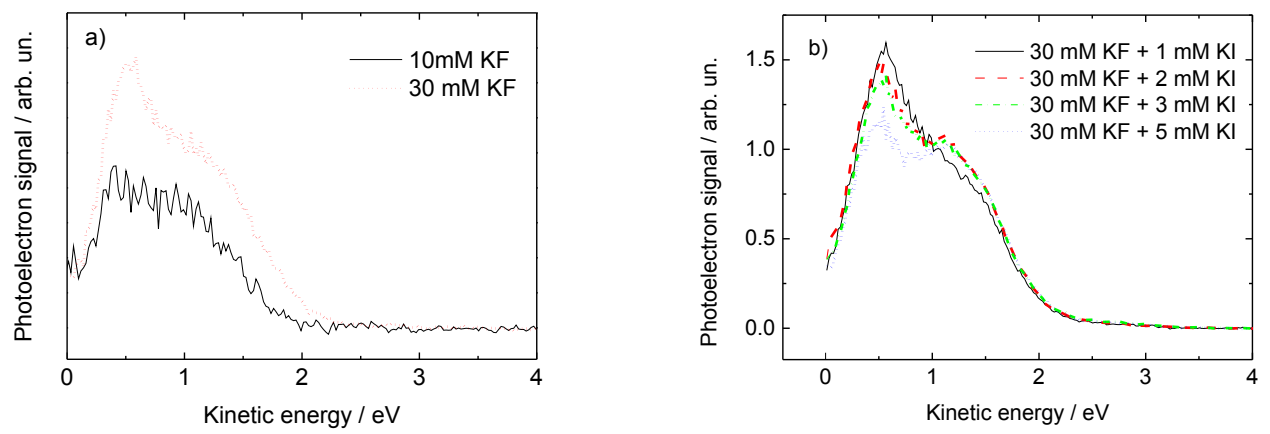

Fig. 2. a) Concentration dependent photoelectron spectra obtained with $800 \mathrm{~nm}$ pulses $(1.55 \mathrm{eV})$ averaged at long delay times ( $5 \mathrm{ps} \leq \Delta \tau \leq 65 \mathrm{ps})$. The contribution at lower kinetic energies $(\leq 1 \mathrm{eV})$ is due to two-photon ionization of the $\left(\mathrm{M}^{+} \ldots \mathrm{e}^{-}\right)_{\text {hyd }}$ and the contribution at larger kinetic energies $(>1 \mathrm{eV})$ due to 3 photon photodetachment of the solvated electron. b) Addition of small amounts of iodide suppresses signal from $\left(\mathrm{M}^{+} \ldots \mathrm{e}^{-}\right)_{\mathrm{hyd}}$.

Our ab initio calculations show that near the surface, and in the presence of cations, the lowest excited state is a charge transfer state. The excited electron resides above the cation at the liquid surface: a hydrated (cation... electron) complex is formed. The positive charge is initially located at one or two water molecules, but rapidly diffuses away due to proton migration. The initial decrease of binding energy reflects this process. The subsequent increase of binding energy is due to solvent shell relaxation of the complex.

We summarize the excited state dynamics of liquid water at the surface under the influence of cations in Fig. 3. Photoexcitation leads to the formation of a charged water molecule and the aforementioned (cation. . .electron) complex. The positively charged water molecule left behind after photoexcitation is not stable, an ultrafast proton transfer occurs leading to formation of $\mathrm{H}_{3} \mathrm{O}^{+}$and an $\mathrm{OH}$ radical $[1,12]$. The formed hydrated (cation. . .electron) complex can react with either $\mathrm{H}_{3} \mathrm{O}^{+}$ions to 


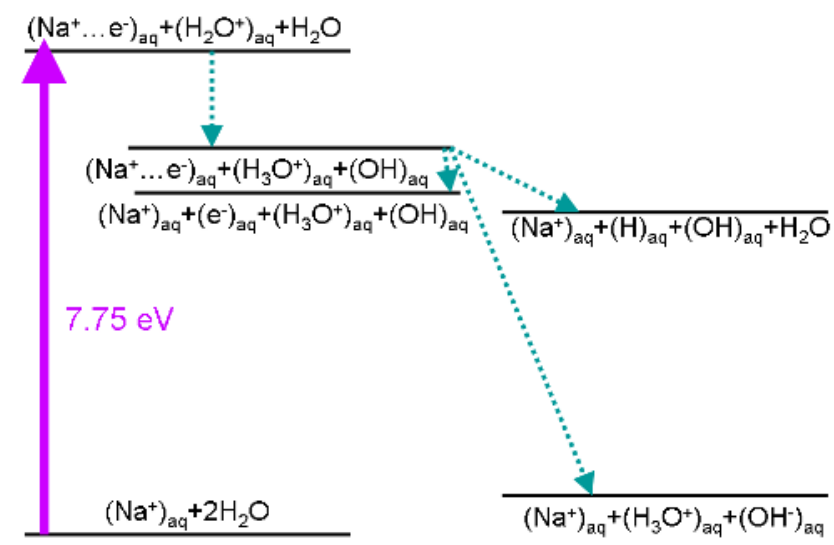

Fig. 3. Proposed photoinduced processes after optical excitation of aqueous Na-salt solution with $7.75 \mathrm{eV}$ photons. After selective excitation of a surface-hydrated (sodium-cation. . .electron) complex, the ionized donor $\mathrm{H}_{2} \mathrm{O}^{+}$ reacts rapidly with water to form $\mathrm{H}_{3} \mathrm{O}^{+}$. Subsequent charge-diffusion and formation of the solvated electron stands in competition with recombination processes.

form hydrogen and water, or with the $\mathrm{OH}$ radical to form $\mathrm{OH}^{-}$. Both reactions can contribute to the fast decay of the complex. The formation of bulk solvated electrons with $3.4 \mathrm{eV}$ binding energy seems to be only of minor importance.

\section{References}

1. B. C. Garrett, D. A. Dixon, D. M. Camaioni, D. M. Chipman, M. A. Johnson, C. D. Jonah, G. A. Kimmel, J. H. Miller, T. M. Rescigno, P. J. Rossky et al., Chem. Rev. 105, (2005) 355

2. A. Ikehata, N. Higashi, and Y. Ozaki, J. Chem. Phys. 129, (2008) 234510

3. P. C. do Coto and D. M. Chipman, J. Chem. Phys. 132, (2010) 244307

4. A. Lübcke, F. Buchner, N. Heine, I. V. Hertel and T. Schultz, Phys. Chem. Chem. Phys. 12, (2010) 14629

5. Y. Tang, Y.-I. Suzuki, H. Shen, K. Sekiguchi, N. Kurahashi, K. Nishizawa, P. Zuo, T. Suzuki, Chem. Phys. Lett. 494, (2010) 111

6. Y.-I. Suzuki, H. Shen, Y. Tang, N. Kurahashi, K. Sekiguchi, T. Mizunoc and Toshinori Suzuki, Chem. Sci. 2, (2011) 1094

7. F. Buchner, A. Lübcke, N. Heine, and T. Schultz, Rev. Sci. Instr. 81, (2010) 113107

8. M. Beutler, M. Ghotbi, and F. Noack, Opt. Lett. 36, (2011) 3726

9. K. R. Siefermann, Y. Liu, E. Lugovoy, O. Link, M. Faubel, U. Buck, B. Winter, and B. Abel, Nature Chem. 2, (2010) 274

10. A. T. Shreve, T. A. Yen, and D. M. Neumark, Chem. Phys. Lett. 493, (2010) 216

11. Y. Tang, H. Shen, K. Sekiguchi, N. Kurahashi, T. Mizuno, Y.-I. Suzuki, and T. Suzuki, Phys. Chem. Chem. Phys. 12, (2010) 3653

12. O. Marsalek, C. G. Elles, P. A. Pieniazek, E. Pluhařová, J. VandeVondele, S. E. Bradforth, and P. Jungwirth, J. Chem. Phys. 135, (2011) 224510

13. F. Buchner, H.-H. Ritze, M. Beutler, T. Schultz, I. V. Hertel, and A. Lübcke, J. Chem. Phys. 137, (2012) 024503 